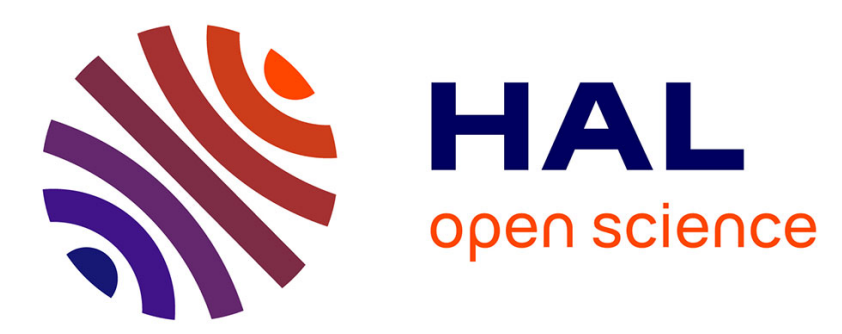

\title{
Oligoester-Derivatized (Semi-) Interpenetrating Polymer Networks as Nanostructured Precursors to Porous Materials with Tunable Porosity
}

D. Grande, Geraldine Rohman

\section{- To cite this version:}

D. Grande, Geraldine Rohman. Oligoester-Derivatized (Semi-) Interpenetrating Polymer Networks as Nanostructured Precursors to Porous Materials with Tunable Porosity. Chemistry Africa, 2019, 2, pp.253-265. 10.1007/s42250-019-00044-3 . hal-03278669

\section{HAL Id: hal-03278669 \\ https://hal.science/hal-03278669}

Submitted on 6 Jul 2021

HAL is a multi-disciplinary open access archive for the deposit and dissemination of scientific research documents, whether they are published or not. The documents may come from teaching and research institutions in France or abroad, or from public or private research centers.
L'archive ouverte pluridisciplinaire HAL, est destinée au dépôt et à la diffusion de documents scientifiques de niveau recherche, publiés ou non, émanant des établissements d'enseignement et de recherche français ou étrangers, des laboratoires publics ou privés. 


\section{Oligoester-Derivatized (Semi-) Interpenetrating}

2 Polymer Networks as Nanostructured Precursors to 3 Porous Materials with Tunable Porosity

5 Daniel Grande ${ }^{1, *}$ and Géraldine Rohman ${ }^{2}$

${ }^{1}$ Institut de Chimie et des Matériaux Paris-Est (ICMPE), UMR 7182 CNRS - Université Paris-

8 Est Créteil, 2, rue Henri Dunant, 94320 Thiais, France

$9 \quad{ }^{2}$ Laboratoire de Chimie, Structures, Propriétés de Biomatériaux et d'Agents Thérapeutiques

10 (CSPBAT), UMR 7244 CNRS - Université Paris-Nord, 74, rue Marcel Cachin, 93017 Bobigny

11 Cedex, France

Submitted as an Original Article to Chemistry Africa

* Corresponding author: Dr. Daniel Grande

Phone: +33 (0)1.49.78.11.77

Fax: +33 (0)1.49.78.12.08

20

E-mail: grande@icmpe.cnrs.fr

ORCID iD : 0000-0002-9987-9961

Acknowledgments: The "Région Ile-de-France" is gratefully acknowledged for financial support through SESAME projects allowing for the purchase of SEM equipment. The authors are indebted to late Prof. Ph. Guérin, Prof. F. 


\section{Abstract}

2 Porous polymeric materials with tunable porosity can be engineered from oligoester3 derivatized semi-Interpenetrating Polymer Networks (semi-IPNs) or IPNs, respectively composed

4 of either uncrosslinked or crosslinked aliphatic oligoesters entangled in a stiff subnetwork. In

5 this paper, miscellaneous polyester/poly(methyl methacrylate)-based semi-IPN and IPN systems

6 are first prepared as precursors with varying structural parameters, especially the nature (i.e., 7 poly(D,L-lactide), poly(E-caprolactone)) and the molar mass (i.e, from 560 to 3,700 g.mol ${ }^{-1}$ ) of

8 the oligoester precursor. (Nano)porous networks with defined porosity are then generated through 9 two complementary routes. This original paper discusses the scope and limitations of both 10 approaches and investigates the correlation between the structure and morphology of the 11 generated networks and the porosity of the resulting porous materials. We demonstrate that the 12 choice of the precursors with defined compatibility is of paramount significance in the length

13 scale of phase separation associated with nanostructured networks aswell as in the porosity scale 14 of (nano)porous materials derived therefrom. Indeed, we find that the quantitative extraction of 15 uncrosslinked oligoesters from semi-IPNs allows for the elaboration of nanoporous networks 16 with pore diameters lower than $150 \mathrm{~nm}$, provided that a high miscibility between both partners in 17 semi-IPN precursors is attained, i.e. when using the lower molar mass oligoester. Alternately, the 18 total hydrolysis of the polyester subnetwork associated with IPNs offers more versatility, since 19 nanoporous networks can be obtained with a pore size range of 20-150 nm, regardless of the 20 oligoester nature and molar mass in IPN precursors.

22 Keywords: Aliphatic oligoesters; (Semi-)Interpenetrating Polymer Networks; Extraction; 23 Hydrolysis; $\quad$ Porous materials; Structure-morphology relationships 


\section{Introduction}

3 The design of functional porous polymeric materials has been the subject of widespread interest

4 and intense research, as they are involved in a wide array of applications, e.g. monoliths for

5 chromatographic techniques, separation membranes, interlayer dielectrics, high surface area

6 catalytic supports, as well as size/shape-selective nanoreactors [1-9]. Besides the classical

7 synthetic strategies that rely on the use of solvents or gases as porogens, original approaches with

8 porogen templates, capable of inducing specific structural pores within the residual structures,

9 have been developed $[10,11]$. These template-oriented routes are quite interesting, since a wide

10 array of porous polymers with a well-defined porosity can be designed.

11 Resorting to (semi-)Interpenetrating Polymer Networks ((semi-)IPNs) as nanostructured

12 precursors to engineer porous crosslinked materials has solely been studied by a few research

13 teams [12-19]. While semi-IPNs are composed of uncrosslinked sub-chains entrapped in a

14 polymer network, IPNs constitute an intimate combination of two independent sub-networks, at

15 least one of which is synthesized in the immediate presence of the other [20-25]. Although IPNs

16 do not generally lead to chain interpenetration at the molecular length scale, small domain sizes

17 from tens to a few hundreds of nanometers can be obtained under synthetically controlled

18 experimental conditions. The peculiar interlocking framework confers to IPNs a microphase-

19 separated co-continuous morphology leading to their unique properties. The IPN morphology

20 essentially depends on the compatibility of each partner (i.e., thermodynamic factor) and the

21 kinetics and mechanism associated with the formation of each sub-network (i.e., kinetic

22 parameters). Nevertheless, if the phase morphology may be varied with several parameters, it has

23 been reported that the phase continuity is controlled by the partner volume fractions and a co- 
1 continuous morphology is generally obtained with a 50/50 composition [21-23]. Moreover, when

2 IPNs are synthesized by the sequential method, i.e. when each sub-network is obtained in two

3 consecutive steps, the first sub-network generally constitutes the most continuous phase and its

4 cross-linking density is an important parameter to control the IPN morphology, while the cross-

5 linking density of the second sub-network has no significant effect [26]. Consequently, the order

6 of the sub-network formation is crucial as different phase morphologies and properties may be

7 obtained. When arising from the combination of two partners that exhibit a contrasted

8 degradability under specific conditions, such complex polymer structures are particularly

9 interesting since nanoporous networks can be generated through selective degradation methods

10 [12-19]. In this regard, IPNs based on a hydrolyzable polyester, such as poly(D,L-lactide) (PLA)

11 or poly(e-caprolactone) (PCL), and a non-hydrolyzable polymer, such as poly(methyl

12 methacrylate) (PMMA), can be considered as appropriate precursors.

13 Straightforward routes to porous cross-linked polymeric materials through the utilization

14 of PLA/PMMA semi-IPNs or IPNs as precursors were previously developed [26,27]. Porous

15 methacrylic networks were readily generated from the quantitative extraction of uncrosslinked

16 PLA oligomers in semi-IPNs or they were engineered from the selective hydrolysis of PLA sub-

17 network in IPNs. The scope and limitations of both systems for the generation of (meso)porous

18 materials were investigated. The effect of the cross-linker nature and the cross-linking density of

19 the PMMA sub-network on the domain sizes in the (semi-)IPN precursors, and the correlation

20 with the pore sizes distributions in the porous materials derived therefrom, were carefully studied.

21 Macro- to mesoporous networks were derived from semi-IPNs and the variation of pore sizes was

22 attributed to the miscibility of both partners in semi-IPN precursors [27]. For IPN systems, the

23 pore sizes were always smaller than $100 \mathrm{~nm}$, regardless of the cross-linker nature and 
1 concentration, which showed that the cross-linking density of the PMMA sub-network and the

2 compatibility between both sub-networks had a relatively small impact on phase separation in

3 IPN precursors [28].

4 In light of the scarcity of studies on porous materials derived from (semi-) IPN systems,

5 we decided to get a better insight into the correlation between the morphology of the (semi-)IPN

6 precursors and the pore sizes of the resulting porous methacrylic networks, and notably on the

7 impact of the molecular features of the first sub-network generated during IPN synthesis (i.e.

8 polyester partner). In the present paper, miscellaneous polyester/PMMA (semi-)IPNs with a

$950 / 50$ composition are prepared to ensure the co-continuity of each phase, and the effect of the

10 nature and molar mass of the oligoester precursor is systematically investigated for the first time.

11 In this regard, poly(D,L-lactide) (PLA) or poly(E-caprolactone) (PCL) oligomers are used with

12 different molar masses. We particularly pay attention to the correlations between the structure

13 and morphology of the (semi-)IPN precursors and the porosity of the resulting porous materials

14 through various physico-chemical analyses, since the control of the precursor miscibility

15 associated with both types of reference systems is of paramount significance for the design of

16 nanoporous materials with defined pore sizes.

\section{$\begin{array}{lll}18 & 2 & \text { Experimental }\end{array}$}

\section{$20 \quad 2.1 \quad$ Materials}

21 Dihydroxy-telechelic PLA oligomers were synthesized by ring-opening polymerization of D,L-

22 lactide initiated by the ethylene glycol/tin (II) octanoate system, according to a literature method

23 [29]. Dihydroxy-telechelic PCL oligomers were purchased from Aldrich. Dibutyltin dilaurate 
1 (DBTDL, Fluka) was used as received. 4,4',4' '-triisocyanato-triphenylmethane (Desmodur ${ }^{\circledR}$ RU;

21.25 mol. $\mathrm{L}^{-1}$ in dichloromethane solution) was provided by Bayer. Methyl methacrylate (MMA,

3 Aldrich) was dried over $\mathrm{CaH}_{2}$, and distilled under vacuum prior to use. Diurethane

4 dimethacrylate (DUDMA) were purchased from Aldrich and used as received. AIBN (Merck)

5 was purified by recrystallization in methanol.

6

$7 \quad 2.2 \quad$ Preparation of Precursory Networks

8 In all experiments, a mold was devised by clamping together two glass plates separated by a 2

9 mm-thick silicone rubber gasket.

$10 \quad$ 2.2.1 Polyester Single Networks

11 Polyester single networks were prepared with a (Oligoester + Desmodur $^{\circledR}$ RU)/dichloromethane

12 mass composition of $50 / 50 \mathrm{wt} \%$ and ratios of $[\mathrm{NCO}]_{0} /[\mathrm{OH}]_{0}$ and $[\mathrm{DBTDL}]_{0} /[\mathrm{O} \text { ligoester }]_{0}$ equal

13 to 1.4 and 0.44 , respectively. An example of the preparation of a PLA single network is given

14 hereafter. $1 \mathrm{~g}$ of PLA $\left(M_{\mathrm{n}}=1,700 \mathrm{~g} \cdot \mathrm{mol}^{-1} ; 5.9 \times 10^{-4} \mathrm{~mol}\right)$ was dissolved in $0.91 \mathrm{~mL}$ of

15 dichloromethane (1.21g), and subsequently, $0.45 \mathrm{~mL}$ of Desmodur ${ }^{\circledR}$ RU $\left(0.21 \mathrm{~g} ; 5.6 \times 10^{-4}\right.$ mol $)$

16 and $0.15 \mathrm{~mL}$ of DBTDL $\left(2.5 \times 10^{-4} \mathrm{~mol}\right)$ were added. The solution was then poured into the mold

17 and kept at room temperature for $20 \mathrm{~h}$. Thereafter, the mold was heated to $65^{\circ} \mathrm{C}$ for $2 \mathrm{~h}$, and then

18 to $110^{\circ} \mathrm{C}$ for $2 \mathrm{~h}$ (Fig. 1).

19 2.2.2 PMMA Single Network

20 An example of the preparation of a single network with a MMA/DUDMA molar composition of

$2190 / 10 \mathrm{~mol} \%$ is given hereafter. A mixture of MMA $\left(0.9 \mathrm{~g} ; 9 \times 10^{-3} \mathrm{~mol}\right)$, DUDMA $\left(0.47 \mathrm{~g} ; 10^{-3}\right.$

$22 \mathrm{~mol})$, and AIBN $\left(0.033 \mathrm{~g} ; 0.2 \times 10^{-3} \mathrm{~mol},[\mathrm{AIBN}]_{0} /\left([\mathrm{MMA}]_{0}+2[\mathrm{DUDMA}]_{0}\right)=0.02\right)$ was 
1 degassed under vacuum, poured under nitrogen into the mold. Then, the mixture was heated at

$265^{\circ} \mathrm{C}$ for $2 \mathrm{~h}$, and cured at $110^{\circ} \mathrm{C}$ for $2 \mathrm{~h}($ Fig. 2).

$3 \quad 2.2 .3$ Oligoester/PMMA Semi-IPNs

4 An example of the preparation of a semi-IPN with a PLA/PMMA mass composition of 50/50 5 wt $\%$ and a MMA/DUDMA molar composition of 90/10 mol\% ([AIBN $]_{0} /\left([\mathrm{MMA}]_{0}+\right.$

$\left.\left.62[\mathrm{DUDMA}]_{0}\right)=0.02\right)$ is given hereafter. $0.50 \mathrm{~g}$ of PLA $\left(M_{\mathrm{n}}=1,700 \mathrm{~g} \cdot \mathrm{mol}^{-1} ; 2.9 \times 10^{-4} \mathrm{~mol}\right)$, $7 \quad 0.33 \mathrm{~g}$ of MMA $\left(3.3 \times 10^{-3} \mathrm{~mol}\right), 0.17 \mathrm{~g}$ of DUDMA $\left(3.6 \times 10^{-4} \mathrm{~mol}\right)$, and $12 \mathrm{mg}$ of AIBN $\left(7.3 \times 10^{-5}\right.$

8 mol) were mixed, degassed under vacuum, and poured into the mold under nitrogen. The system

9 was then heated to $65^{\circ} \mathrm{C}$ for $2 \mathrm{~h}$, and cured at $110^{\circ} \mathrm{C}$ for a $2 \mathrm{~h}($ Fig. 3).

$10 \quad$ 2.2.4 Polyester/PMMA IPNs

11 An example of the preparation of an IPN with a PLA/PMMA mass composition of 50/50 wt\%, 12 ratios of $[\mathrm{NCO}]_{0} /[\mathrm{OH}]_{0}$ and $[\mathrm{DBTDL}]_{0} /[\mathrm{O} \text { ligoester }]_{0}$ equal to 1.4 and 0.44 , respectively, and a 13 MMA/DUDMA molar composition of 90/10 mol\% $\left([\mathrm{AIBN}]_{0} /\left([\mathrm{MMA}]_{0}+2[\mathrm{DUDMA}]_{0}\right)=0.02\right)$ 14 is given hereafter. $1 \mathrm{~g}$ of PLA $\left(M_{\mathrm{n}}=1,700 \mathrm{~g} \cdot \mathrm{mol}^{-1} ; 5.9 \times 10^{-4} \mathrm{~mol}\right), 0.76 \mathrm{~g}$ of MMA $\left(7.6 \times 10^{-3}\right.$ $15 \mathrm{~mol}), 0.40 \mathrm{~g}$ of DUDMA $\left(8.5 \times 10^{-4} \mathrm{~mol}\right)$, and $27.7 \mathrm{mg}$ of AIBN $\left(1.7 \times 10^{-4} \mathrm{~mol}\right)$ were mixed and 16 degassed under vacuum. Then, $0.45 \mathrm{~mL}$ of Desmodur ${ }^{\circledR} \mathrm{RU}\left(0.21 \mathrm{~g} ; 5.6 \times 10^{-4} \mathrm{~mol}\right)$ and $0.15 \mathrm{~mL}$ of

17 DBTDL $\left(2.5 \times 10^{-4} \mathrm{~mol}\right)$ were added under nitrogen, and the solution was poured into the mold 18 and kept at room temperature for $20 \mathrm{~h}$.. Finally, the system was heated to $65^{\circ} \mathrm{C}$ for $2 \mathrm{~h}$, and cured 19 at $110^{\circ} \mathrm{C}$ for $2 \mathrm{~h}$ (Fig. 4).

Other single polyester networks and (semi-)IPNs were synthesized in similar ways by changing the nature and/or the molar mass of the oligoester precursor. 


\subsection{Extraction of Networks and Formation of Porous Networks from Semi-IPNs}

2 All networks and (semi-)IPNs were Soxhlet extracted with dichloromethane for $24 \mathrm{~h}$ at $40^{\circ} \mathrm{C}$.

3 After extraction, the samples were dried under vacuum, weighed, and the sol fractions (mass

4 percentages of extractables) were calculated. The extraction of linear oligoesters from semi-IPNs

5 led to the formation of residual porous PMMA networks (Fig.3).

\section{$7 \quad 2.4 \quad$ Formation of Porous Networks by Partial Hydrolysis of IPNs}

$8 \quad 0.2 \mathrm{~g}$ of IPNs were immersed at $60^{\circ} \mathrm{C}$ in a mixture composed of $4 \mathrm{~mL}$ of a methylamine solution

$9 \quad(\mathrm{pH}=13.6)$ and $4 \mathrm{~mL}$ of ethanol. After $24 \mathrm{~h}$, the residual networks were rinsed with deionized

10 water up to neutral $\mathrm{pH}$, and dried under vacuum. The mass loss $(\Delta m)$ was assessed as follows

11 (Equation 1):

$12 \Delta m(\mathrm{wt} \%)=100 \times\left(m_{0}-m_{\mathrm{d}}\right) / m_{0}$

13 where $m_{0}$ and $m_{\mathrm{d}}$ stand for the initial mass of the samples and their residual mass after vacuum

14 drying, respectively.

15 The total hydrolysis of the polyester sub-network led to the formation of residual porous

16 PMMA networks (Fig.4).

\section{$\begin{array}{lll}18 & 2.5 & \text { Instrumentation }\end{array}$}

19 FTIR spectra were recorded between 4,000 and $450 \mathrm{~cm}^{-1}$ by averaging 32 consecutive scans with 20 a resolution of $4 \mathrm{~cm}^{-1}$ on a Bruker Tensor 27 DTGS spectrometer in Attenuated Total Reflection 21 (ATR) mode.

DSC thermograms were recorded with a Perkin Elmer DSC7 calorimeter under nitrogen

23 atmosphere. The analyses were carried out at a heating rate of $20^{\circ} \mathrm{C} \cdot \mathrm{min}^{-1}$ and the second run was

24 performed after quenching. In order to avoid network degradation during the analysis, PMMA 
1 single networks and (semi-)IPNs were scanned twice from -100 to $200^{\circ} \mathrm{C}$, while polyester single

2 networks and oligoester precursors were scanned from -100 to $100^{\circ} \mathrm{C}$ and from -100 to $200^{\circ} \mathrm{C}$

3 for the first and second scans, respectively. The $T_{\mathrm{g}}$ ranges were measured in the second run

4 through the determination of the values associated with the intercepts of tangent to midpoint of

5 the specific heat increment with "glassy"(lower limit, $T_{\mathrm{g}, \mathrm{onset}}$ ) and "viscous" baselines (upper

6 limit, $\left.T_{\mathrm{g}, \text { end }}\right)$, respectively.

$7 \quad{ }^{1} \mathrm{H}$ and ${ }^{13} \mathrm{C}$ spectra of sol fractions and hydrolysis products were recorded at room

8 temperature using a Bruker Avance II spectrometer operating at a resonance frequency of 400

9 and $100 \mathrm{MHz}$, respectively. The sample concentration was $10 \mathrm{mg} \cdot \mathrm{mL}^{-1}$, and $\mathrm{CDCl}_{3}$ was used as

10 the solvent and internal standard (7.27 ppm).

11 The Size Exclusion Chromatography (SEC) equipment comprised a Spectra Physics P100

12 pump, two PLgel $5 \mu \mathrm{m}$ mixed-C columns (Polymer Laboratories), and a Shodex RI 71 refractive

13 index detector. Tetrahydrofuran (THF) was used as the eluent at a flow rate of $1 \mathrm{~mL} \cdot \mathrm{min}^{-1}$, and

14 polystyrene standards (Polymer Laboratories) were employed for calibration.

15 Scanning Electron Microscopy (SEM) analyses were performed with a LEO 1530

16 microscope equipped with a high-vacuum $\left(10^{-10} \mathrm{mmHg}\right)$ Gemini column. The accelerating

17 tensions ranged from 1 to $5 \mathrm{kV}$; two types of detectors (InLens and Secondary Electron) were

18 used. Prior to analyses, the samples were cryofractured and coated with a Pd/Au alloy (4 nm) in a

19 Cressington 208 HR sputter-coater.

\section{$21 \quad 2.6 \quad$ Thermoporometry by DSC}

22 The pore size and pore size distribution of the porous materials were determined through

23 thermoporometry based on the melting temperature $\left(T_{\mathrm{m}}\right)$ depression of a liquid constrained within 
1 the pores [30-32]. To this purpose, the samples were immersed in ethanol for $2 \mathrm{~h}$, and then placed

2 for $1 \mathrm{~h}$ in ethanol/water mixtures of various compositions (70/30, 50/50, 30/70 vol\%). After a 2

3 week immersion in pure water, the melting thermograms of wiped samples were recorded from -

450 to $5^{\circ} \mathrm{C}$ at a heating rate of $1^{\circ} \mathrm{C} \cdot \mathrm{min}^{-1}$.

5 The pore size distribution was obtained by plotting $\mathrm{d} V / \mathrm{d} R$ vs. the pore diameter $\left(D_{\mathrm{p}}\right)$

6 evaluated by using Equation 2 and 3, respectively [30-32]:

$7 \quad \mathrm{~d} V / \mathrm{d} R\left(\mathrm{~cm}^{3} \cdot \mathrm{nm}^{-1} \cdot \mathrm{g}^{-1}\right)=\left[(\mathrm{d} q / \mathrm{d} t) \times\left(T_{\mathrm{m}}-T_{\mathrm{m} 0}\right)^{2}\right] /[32.33 \times \rho \times v \times m \times \Delta H(\mathrm{~T})]$

$8 D_{\mathrm{p}}(\mathrm{nm})=2 \times\left[0.68-32.33 /\left(T_{\mathrm{m}}-T_{\mathrm{m} 0}\right)\right]$

9 where $T_{\mathrm{m}}$ and $T_{\mathrm{m} 0}$ are the melting temperatures of confined and bulk water, respectively, and

$10 \mathrm{~d} q / \mathrm{d} t, \rho, v, m$ and $\Delta H(\mathrm{~T})$ are the heat flow recovered by DSC, the water density, the heating rate,

11 the sample mass and the melting enthalpy of water, respectively. $\Delta H(T)$ was calculated from

12 Equation 4 [30-32]:

$13 \Delta H(\mathrm{~T})\left(\mathrm{J} . \mathrm{g}^{-1}\right)=332+1.39 \times\left(T_{\mathrm{m}}-T_{\mathrm{m} 0}\right)+0.155 \times\left(T_{\mathrm{m}}-T_{\mathrm{m} 0}\right)^{2}$

\section{$15 \quad 2.7 \quad$ Determination of Density and Porosity Ratio Values}

16 The samples were immersed in ethanol for $2 \mathrm{~h}$, and then placed for $1 \mathrm{~h}$ in ethanol/water mixtures

17 of various compositions (70/30, 50/50, 30/70 vol\%). After a 2 week immersion in pure water, the

18 wet mass was measured, and the mass swelling ratio $\left(q_{\mathrm{w}}\right)$, the pore volume $\left(V_{\text {pore }}\right)$, and the

19 apparent density ( $\left.d_{\mathrm{app}}\right)$ were calculated from Equation 5, 6 and 7, respectively [33]:

$20 \quad q_{\mathrm{w}}=m_{w} / m_{d}$

$21 V_{\text {pore }}\left(\mathrm{cm}^{3} \cdot \mathrm{g}^{-1}\right)=\left(q_{\mathrm{w}}-1\right) / d_{\mathrm{s}}$

$$
V_{\text {pore }}=1 / d_{\text {app }}-1 / d_{\text {true }}
$$


1 where $m_{\mathrm{w}}, m_{\mathrm{d}}, d_{\mathrm{s}}$ and $d_{\text {true }}$ stand, respectively, for the samples wet mass, their mass after vacuum

2 drying, the solvent density (water), and the true density of the PMMA matrix measured by helium

3 pycnometry at $25^{\circ} \mathrm{C}$ by using A Micromeritics Accupyc 1330 equipment.

4 The porosity ratio $P$ was then calculated by using Equation 8:

$5 \quad P=1-d_{\text {app }} / d_{\text {true }}$

6

$7 \quad 3 \quad$ Results and Discussion

$9 \quad 3.1 \quad$ Preparation of Semi-IPN Precursors and Investigation of Phase Separation

10 Various Oligoester/PMMA (50/50 wt\%) semi-IPNs were prepared by bulk free-radical 11 copolymerization of MMA and DUDMA with a composition of 90/10 mol\%, in the presence of 12 oligoesters of different natures and molar masses (Table 1). The radical polymerization occurred 13 at $65^{\circ} \mathrm{C}$ and the cross-linking completion arose during the final curing at $110^{\circ} \mathrm{C}$ (Fig. 3), which 14 was confirmed by the absence of the $\mathrm{C}=\mathrm{C}$ absorption band of MMA and dimethacrylate 15 monomers at $1,640 \mathrm{~cm}^{-1}$ in the FTIR spectra. In a previous study concerning the kinetics of 16 network formation, it was shown that "soft" oligoesters behaved like a diluent toward the 17 methacrylic copolymerization process which led to the complete conversion of $\mathrm{C}=\mathrm{C}$ bonds before 18 the curing process [25]. Moreover, the kinetic process was not greatly affected by the variation 19 of the polyester nature or molar mass (data not shown).

For (semi-)IPN-related materials [21,22], the turbidity $\tau$, which corresponds to the relative

22 attenuation of light by the materials, accounts for the degree of chain interpenetration and allows

23 for the determination of the microdomain size, provided the difference between the refractive 
1 indices of both partners is significant $(\Delta \mathrm{n} \geq 0.02)$. Indeed, microdomain sizes are smaller than

2 about150 nm when materials are transparent, while the opaque ones possess microdomain sizes

3 higher than $150 \mathrm{~nm}$ [34]. Table 2 reports the different visual aspects observed for semi-IPNs

4 before extraction. In the case of PLA-based semi-IPNs, the experimental $\mathrm{n}_{\mathrm{D}}{ }^{25}$ values measured

5 for the PLA oligomer and a PMMA network were quite different $\left(\mathrm{n}_{\mathrm{D}}{ }^{25}\right.$ PLA $=1.46, \mathrm{n}_{\mathrm{D}}^{25}$ PMMA $=$

6 1.49), and therefore the material turbidity can be used to evaluate the effect of the oligoester

7 molar mass on the phase separation. It is noteworthy that the increase in the PLA molar mass led

8 to an increase in the oligoester domain sizes, as semi-IPNs were transparent when the molar mass

9 of the oligomer was equal to $570 \mathrm{~g} \cdot \mathrm{mol}^{-1}$ and opaque when the latter was equal to $3,700 \mathrm{~g} \cdot \mathrm{mol}^{-1}$.

10 For PCL-based semi-IPNs, the $\mathrm{n}_{\mathrm{D}}{ }^{25}$ values of PMMA sample and PCL oligomer $\left(\mathrm{n}_{\mathrm{D}}{ }^{25} \mathrm{PCL}=1.49\right)$

11 were quite identical, and it was consequently difficult to take into account the transparency of the

12 samples. Nevertheless, there was clearly a phase separation when the samples were opaque.

13 Consequently, it was possible to conclude that PCL oligomers led to higher oligoester domain

14 sizes compared to PLA oligomers with the same molar mass, as semi-IPNs were opaque with

15 PCL 2,100 g.mol ${ }^{-1}$ and translucent for PLA 1,700 g.mol ${ }^{-1}$.

Semi-IPN samples, before extraction,displayed single and fairly narrow glass

18 transitionranges (Table 2).The $T_{\mathrm{g}}$ values were quite low but comprised between the $T_{\mathrm{g}}$ of

19 corresponding oligoester (Table 1) andthat of PMMA single network (Table 3). Yet, the $T_{\mathrm{g}}$ ranges

20 of semi-IPNs did not match the valuescalculated from the Fox equation for miscible blends. For

21 PLA-based semi-IPNs, the transparent aspect of the samples solely argued in favor of the absence

22 ofphase separation at a length scale of a few hundreds ofnanometers. Moreover, the values of the

23 heat capacity jump at theglass transition $\left(\Delta C_{\mathrm{p}}\right)$ decreasedwhen the molar mass of the PLA 
1 oligomers increased and became smaller than the values obtained for a 50/50 wt $\%$ physical blend

2 constituted of PLAoligomer and PMMApreparedunder experimental conditions identical tothose

3 employed for single network preparation $\left(\Delta C_{\mathrm{p}}=0.33 \mathrm{~J} \cdot \mathrm{g}^{-1} .{ }^{\circ} \mathrm{C}^{-1}\right)$. This result also corroborated the

4 conclusionsinferred from the visual observations concerning the increase in phase separation

5 when using oligomers with higher molar masses. In the case of PCL oligomers, the values of

$6 \Delta C_{\mathrm{p}}$ found for miscible blends were 0.18 and $0.28 \mathrm{~J}_{\mathrm{g}}{ }^{-1} .{ }^{\circ} \mathrm{C}^{-1}$ for PCL 560 and 2,100 g.mol ${ }^{-1}$,

7 respectively. As a consequence, both PCL-containing semi-INPs exhibited a phase separation at

8 the length scale of a few hundred nanometers. One more time, the phase separation was found

9 higher for PCL-based semi-IPNs compared to PLA ones with the same molar mass as the

10 differences between the values of $\Delta C_{\mathrm{p}}$ for semi-IPNs and those for miscible blends increased.

11 Finally, a decrease in the enthalpy of melting and inthe crystallinitydegree of PCL oligomers

12 were observed in semi-IPNs as PMMA hindered the oligoester crystallization [34].

13 In a previous paper [24], we already related the dependence of domain size to the

14 polymer-polymer miscibility in semi-IPN precursors, thanks to the calculation of PLA/PMMA

15 interaction parameters $(\chi)$ and critical interaction parameters $\left(\chi_{\mathrm{cr}}\right)$. We hypothesized that the

16 domain sizes could be tuned by varying structural parameters through the variation of miscibility

17 between the oligoester and the PMMA sub-network. In order to confirm this idea, we also

18 evaluated these parameters in PLA/PMMA and PCL/PMMA semi-IPNsunder investigation, and

19 we studied the effect of the variation of the oligoester molar mass. Because relatively weak

20 interactions (van der Waals forces or hydrogen bonds) are involved in the systems under study,

21 the $\chi$ values could be related to the Hildebrand solubility parameters of both partners using

22 Equation9 [35-38]:

$23 \quad \chi=\frac{\mathrm{V}_{\mathrm{m}}}{\mathrm{R} \cdot \mathrm{T}} \cdot\left(\delta_{1}-\delta_{2}\right)^{2}$ 
1 where $V_{\mathrm{m}}$ and Tare the reference molar volume andthe temperature, taken as $100 \mathrm{~cm}^{3} \cdot \mathrm{mol}^{-1}$ and

$2298 \mathrm{~K}$,respectively, Ris the gas constant, $\delta_{1}$ is the solubilityparameter of oligoester, and $\delta_{2}$ is the

3 solubility parameter ofa methacrylic copolymer network.

$4 \quad \delta_{1}$ was calculatedusing the group contribution method based on VanKrevelen's molar attraction

5 constants: ${ }^{29} \delta_{1}=18.56 \pm 0.15 \mathrm{MPa}^{1 / 2}$ for PLA and $\delta_{1}=17.94 \pm 0.15 \mathrm{MPa}^{1 / 2}$ for PCL. $\delta_{2}$ was

6 calculatedusing an additive molar contribution relationship and was found to equal $20.76 \pm 0.15$

$7 \mathrm{MPa}^{1 / 2}$ for a 90/10 mol\% MMA/DUDMA network [26]. As a matter of fact, the values of $\chi w e r e$

$8 \quad 0.19 \pm 0.05$ and $032 \pm 0.07$ for PLA/PMMA and PCL/PMMA semi-IPNs, respectively. As the $\chi$

9 value was higher for PCL-based systems, it could be concluded that PCL oligomers led to less

10 miscibility with the PMMA sub-network in semi-IPN precursors. To evaluate the influence of

11 oligoester molar masson the miscibility of both semi-IPN partners, $\chi_{\text {cr }}$ were estimated for

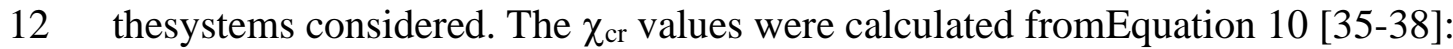

$13 \quad \chi_{\mathrm{cr}}=\frac{1}{2} \cdot\left(\frac{1}{\sqrt{\mathrm{N}_{1}}}+\frac{1}{\sqrt{\mathrm{N}_{2}}}\right)^{2}$

14 where $N_{1}$ and $N_{2}$ are the polymerization degrees of oligoester and PMMA sub-networks,

15 respectively. Whena polymer is cross-linked, Nis equal to infinity; hence, the latter equation could

16 simply be expressed as follows(Equation 11):

$17 \quad \chi_{\mathrm{cr}}=\frac{1}{2 \cdot \mathrm{N}_{1}}$

18 Applying Equation12 to the PLA and PCL oligomers used in thisinvestigation, the value of

$19 \chi_{\mathrm{cr}}$ could be calculated. Nevertheless, it should be stressed that these valuesare valid for systems

20 withonly dispersive forces. According to Coleman's practicalguide to polymer miscibility

21 [37], $\Delta \delta_{\text {cr }}$ can be increased bysteps of $0.25\left(\mathrm{cal}_{\mathrm{c}} \mathrm{cm}^{-3}\right)^{1 / 2}$, depending on the strength ofthe potential 
1 intermolecular interactions present betweenthe polymeric components of biphasic systems.In

2 DUDMA-based semi-IPNs,hydrogen bonding could potentially be established betweenthe

3 urethane functions of DUDMA cross-linksand the main-chain ester groups of oligoester. We

4 previously demonstrated that theextent of hydrogen bonding, so in turn the strength

5 ofintermolecular interactions, could be increased withincreasing amounts of DUDMA [26].

6 Therefore, $\Delta \delta_{\text {cr }}$ wasfurther increased depending on the DUDMA content. The initial $\Delta \delta_{\text {cr }}$ values

7 were estimated for each oligoesters using the reference molar volume of $57.7 \mathrm{~cm}^{3} \cdot \mathrm{mol}^{-1}$ and

$8 \quad 106.5 \mathrm{~cm}^{3} \cdot \mathrm{mol}^{-1}$ for PLA and PCL, respectively. After the appropriate step increase for $10 \mathrm{~mol} \%$

9 DUDMA-based systems [26], $\chi_{\mathrm{cr}}$ values were calculated and are given in Table 4. Consequently,

10 these values showed that the miscibility decreased when the oligoester molar mass increased as

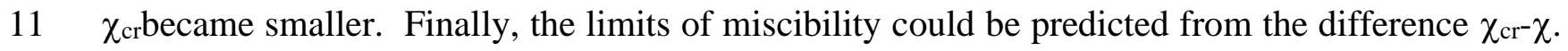

12 Indeed, when the value of $\chi_{\mathrm{cr}-} \chi>0$, the system can be considered to be miscible, while it is

13 immiscible if $\chi_{\mathrm{cr}-} \chi<0$. Therefore, $10 \mathrm{~mol} \%$ DUDMA-based semi-IPNs containing PLA 570

14 g.mol ${ }^{-1}$ would not exhibit phase separation, while PLA 3,700 g.mol ${ }^{-1}$ or PCL 2,100 g.mol ${ }^{-1}$-based

15 systems should. At least, PLA 1,700 and PCL 560 g.mol ${ }^{-1}$-based systemswere in the limit of

16 phase separation as the values of $\chi_{\mathrm{cr}-} \chi$ were around 0 . To conclude, this theoretical approach may

17 well account for the different behaviourstowards phase separation in semi-IPNs when varying the

18 oligoester nature or molar mass. Indeed, thecalculation of oligoester/PMMA interaction

19 parameters andthe comparison between $\chi$ and $\chi_{\mathrm{cr}}$ values corroborated the conclusions inferred

20 from our previous results associated with DSC analysis and visual aspects. 
1 IPNs constituted of polyester and PMMA sub-networks (50/50 wt\%) were synthesized by the in

2 situ sequential method, i.e. by mixing all the precursors homogeneously, and then forming both 3 networks via two successive and non-interfering cross-linking reactions. Hence, the

4 polyestersub-network was first generated at room temperature for $20 \mathrm{~h}$ by DBTDL-catalyzed 5 cross-linking of dihydroxy-telechelic oligoesters(molecular characteristics described in Table 1)

6 with a pluriisocyanate, i.e.Desmodur ${ }^{\circledR}$ RU. Subsequently, the methacrylic sub-network was

7 created at $65^{\circ} \mathrm{C}(2 \mathrm{~h})$ by $\mathrm{AIBN}$-initiated free-radical copolymerization of MMA and DUDMA

8 with a molar ratio of $90 / 10$, and finally cured at $110^{\circ} \mathrm{C}$ for $2 \mathrm{~h}$ to ensure a near completion of the

9 cross-linking processes (Fig. 4) [27,39,40].Next, the IPN samples were extracted in a Soxhlet

10 device with $\mathrm{CH}_{2} \mathrm{Cl}_{2}$ for $24 \mathrm{~h}$, and the amounts of soluble fractions are reported in Table 5.The

11 soluble fractions were always below $14 \mathrm{wt} \%$ which matched with the sum of the corresponding

12 polyester and PMMA single networks soluble fractions, except for PLA 3,700 g.mol ${ }^{-1}$-based

13 IPNs in which soluble fractions were very high. In the latter case, the SEC analysis of the soluble

14 fractions showed that they were constituted in majority of PLA oligomer precursors (around

$1585 \%$ ). DBTDL, PMMA oligomers, and only traces of residual methacrylates were also found by

$16{ }^{1} \mathrm{H}$ NMR. On the contrary, a high ratio of PMMA with molar mass ranging from 100 to 60,000

17 g.mol ${ }^{-1}$ was extracted from PLA 570 g.mol-1-based IPNs, and a higher content of residual

18 methacrylates was also found. However, the IRTF study of networks after extraction revealed

19 that hydroxyl groups were still present in IPNs synthesized from oligoester with low molar mass

20 which indicated that the cross-linking of polyester sub-network was not complete. The variations

21 of the kinetic process of the polyester sub-network with the oligoester precursor molar

22 masswerenot studied as the Lambert-Beer Law was not valid for low molar mass. 
Concerning the PMMA-sub-network formation, we showed in a previous study [27] that

2 the "soft" polyester sub-network acted as a diluent towards the methacrylic copolymerization

3 process, preventing the reaction medium from attaining the glassy state as a solvent would have

4 done it. However, as the free-radical polymerization proceeded, the $T_{\mathrm{g}}$ of the system

5 increasedand the temperature of the reaction medium, i.e. $65^{\circ} \mathrm{C}$, was around the $T_{\mathrm{g}}$ values of IPNs

6 (Table 6). Therefore, the polymerization was considered to take place in a confined medium

7 (into the polyester sub-network matrix) and was going to stop unless the temperature was

8 increased to $110^{\circ} \mathrm{C}$.We also found that the kinetic process was not greatly affected by the

9 variation of the polyester nature or molar mass (data not shown).

10 Interestingly, all IPNs were transparent indicating that domain sizeswere always smaller

11 than $150 \mathrm{~nm}$ as the difference between the refractive indices ofboth sub-networkswas significant

$12(\Delta \mathrm{n} \geq 0.02)$. Actually, theexperimental $\mathrm{n}_{\mathrm{D}}{ }^{25}$ values measured for the PLA and PCL sub-networks

13 were equal to 1.51 and 1.53 , respectively, while that for PMMA sub-network was equal to

14 1.49.Such visual observations showed that chain interpenetration of both polyester and PMMA

15 sub-networks in the interlocking configuration of IPNs led to a significant decrease in the phase

16 separation compared to the corresponding semi-IPN homologues. This was particularly true for

17 systems with a higher degree of immiscibility like those with PLA 3,700 g.mol ${ }^{-1}$ and PCL 2,100

18 g.mol ${ }^{-1}$ as the semi-IPNs synthesized with these oligomers were opaque.

19 DSC analyses also confirmed the decrease in phase separation in IPNs (Table 6). Indeed,

20 all IPNs displayed single glass transition ranges comprised between the $T_{\mathrm{g}}$ of corresponding

21 polyester sub-networks and that of PMMA single network (see Table 3), which argued in favor

22 of the absence of phase separation at a length scale of a few hundreds of nanometers. No melting

23 temperatures were detected in PCL-based IPNs, as the oligoester cross-linking totally prevented 
1 PCL crystallization. Moreover, the values of the heat capacity jump at the glass transition $\left(\Delta C_{\mathrm{p}}\right)$

2 were always equalor close to the expected $\Delta C_{\mathrm{p}}$ value of a $50 / 50 \mathrm{wt} \%$ physical blend theoretically

3 constituted of polyester and PMMA networks $\left(\Delta C_{\mathrm{p} \text {,theoretical }}=0.25 \mathrm{~J}_{\mathrm{g}}{ }^{-1} \cdot{ }^{\circ} \mathrm{C}^{-1}\right)$, except for PCL

42,100 g.mol ${ }^{-1}$-based IPNs. Nevertheless, the $\Delta C_{\mathrm{p}}$ values decreased when the oligoester precursor

5 molar mass increasedshowing that the domain sizes were still higher for these systems, like in the

6 case of semi-IPN systems. This was very clear when using PCL 2,100 g.mol ${ }^{-1}$ as the value of

$7 \Delta C_{\mathrm{p}}$ was equal to only $0.14 \mathrm{~J} \cdot \mathrm{g}^{-1} \cdot{ }^{\circ} \mathrm{C}^{-1}$. This trend was also supportedby the increase in $\Delta T_{\mathrm{g}}$ with the

8 oligoester precursor molar mass.All these results confirmed that the phase separation in IPNs was

9 mainly governed by the interpenetration created by the cross-linking of both partners, preventing

10 any phase segregation at the nanoscopic scale $[27,39,40]$.

\section{$12 \quad 3.3 \quad$ Generation of Porous Networks from Semi-IPNs}

13 Porous methacrylic networks were obtained by mere extraction of the un-crosslinked oligoesters 14 from oligoester/PMMA (50/50 wt\%) semi-IPNs (Fig. 3). One such extraction was performed 15 with a good solvent of oligoesters at a temperature $\left(40^{\circ} \mathrm{C}\right)$ far below the $T_{\mathrm{g}}$ value of PMMA 16 network to avoid the collapse of the residual porous structures [26,41-43]. The amounts of

17 soluble fractions are reported in Table 5. Regardless of the oligoester nature and molar mass, the

18 extraction of linear oligomers was quantitative as indicated by extractable contents higher than or

19 equal to $50 \mathrm{wt} \%$. Furthermore, ${ }^{1} \mathrm{H}$ NMR and SEC analyses of the soluble fractions showed that

20 they were constituted of more than $95 \%$ of oligoester precursor. No undesired grafting of PLA or

21 PCL sub-chains onto PMMA sub-networks through transfer reactions was detected in the present

22 systems. The total disappearance of the characteristicbands associated with $\alpha, \omega$-dihydroxy-

23 oligoester (hydroxyland carbonyl groups) in the FTIR spectra of semi-IPNs afterextraction 
1 confirmed the latter assertion. DSC analyses (Table 2) showed that the $T_{\mathrm{g}}$ and $\Delta C_{\mathrm{p} v a l u e s}$ of

2 semi-IPNs after extraction matched pretty well those of the correspondingsingle network (Table

3 3). This arose from thequantitative extraction of oligoesters. Nevertheless for PLA 3,700 g.mol ${ }^{-1}$ -

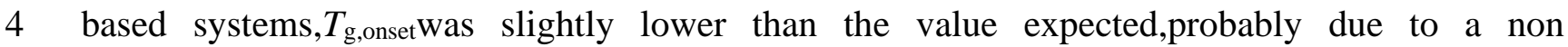

5 quantitative extraction as shown also by anextractable content of $48 \%$.

6 The morphologiesof semi-IPNs after extraction were examinedby SEM (Fig.5).The

7 micrographs revealed highly porous structures, thus showing the effective role of oligoesters as

8 template porogens. Pore sizes strongly depended on the oligoester nature and molar mass.

9 Indeed, pore diameters were as large as $450 \mathrm{~nm}$ for PLA-based systems and 1,000 nm for PCL-

10 based-system homologues. Moreover, pore sizes clearly increased when increasing the oligoester

11 molar mass (Table 7). The pore size distributions were also determined through DSC-based

12 thermoporometry using water as the penetrant solvent. We already used this technique for the

13 determination of pore size distributions in (semi-)IPNs which also gave complementary results

14 compared to SEM analysis, as thermoporometry allows for the measurement ofthe smallerpore

15 diameters $(<200 \mathrm{~nm})$ [26,27]. The pore size ranges are reported in Table 7 and pore size

16 distributions are shown in Fig.6a. Overall, the pore sizes obtained by SEM and those determined

17 by thermoporometry were in reasonable agreement. Finally, the dependence of pore sizes in such

18 porous materialsmirrored the differences observed in semi-IPNprecursors from visual aspects,

19 DSC analysis, and polymer-polymer miscibility inferred from thecalculation of

20 oligoester/PMMA interaction parameters. To conclude, the miscibility of both partners in semi-

21 IPN systems is the most essential parameter controlling the pore size distribution after extraction.

22 Nanoporous structures with poressmaller than $150 \mathrm{~nm}$ could be engineeredwhen usinga PLA 
1 oligomer with amolar mass lower than around 2000 g.mol ${ }^{-1}$, while a PCL oligomer with the

2 latter molar mass led to a porous structure with a very broad pore size distribution.

Pore volumes of porous networks were obtained through mass swelling ratio in water and

4 led to the determination of apparent density and porosity ratio values (Table 8). Porosity

5 ratioswere all around $50 \mathrm{vol} \%$ which matched the expected values, taking into account the

6 quantitative extraction of linear oligoesters from semi-IPNs with a 50/50 wt $\%$ oligoester/PMMA

7 composition.As also seen in SEM micrographs, this strongly indicated that the porous networks

8 were monolithic structures constituted of open pores or interconnected channels through which a

9 fluid could circulate. Moreover, the porous samples were wrapped in apolyethylene film and

10 placed in $n$-pentane $\left(d_{20^{\circ} \mathrm{C}}=0.624\right)$ : in such a low-density solvent, they did float,thus confirming

11 apparent density as well as porosityratio values lower than or equal to values around 0.6.

\section{$13 \quad 3.4 \quad$ Engineering Nanoporous Networks from IPNs}

14 Porous networks were produced by an original approach through the total hydrolysis of the 15 polyester sub-network associated with partially hydrolyzable polyester/PMMA (50/50 wt $\%$ ) IPNs

$16[27,39,40]$. Advantage of the contrasted hydrolytic degradability of aliphatic polyesters and

17 PMMA was thus taken. The degradation was conducted for $24 \mathrm{~h}$ at $60^{\circ} \mathrm{C}$ using a $50 / 50 \mathrm{vol} \%$

18 mixture of methylamine $(\mathrm{pH}=13.6)$ and ethanol. It has to be stressed that the hydrolysis was

19 performed at an intermediate temperature between the $T_{\mathrm{g}}$ of polyester single networks and that of

20 PMMA single network to avoid the collapse of the residual porous methacrylic structures, while

21 allowing for an efficient degradation of the polyester partner. The role of ethanol wasdual: $(i)$

22 increasing the hydrophilic behaviour of the methacrylic sub-network, thusenabling a better

23 diffusion of the medium into the IPN structure [44,45], and (ii) increasing the diffusion rate of the

24 degradation products outside the networkas ethanol is a good solvent of oligoesters. With these 
1 conditions, PLA- and PCL-based single networks were completely hydrolyzed after $5 \mathrm{~min}$ and

$23.5 \mathrm{~h}$, respectively, while no mass loss was detected for $10 \mathrm{~mol} \%$ DUDMA-based single

3 networks. Table 5 gives the mass losses obtained after hydrolysis of IPNs. Regardless of the

4 oligoester precursor nature or molar mass, mass loss values close to $50 \mathrm{wt} \%$ were determined,

5 which demonstrated a nearly quantitative degradation of the oligoester-derivatized sub-

6 networkfrom polyester/PMMA (50/50 wt $\%$ ) IPNs. Moreover, the total disappearance of the

7 characteristic bands associated with polyester sub-networks (urethane and carbonyl groups) in the

8 FTIR spectra of residual networks after hydrolysis confirmed their methacrylic structure.

9 Nevertheless, in comparison to the corresponding PMMA single network, the residual

10 methacrylic networks, after IPN hydrolysis, exhibited a low intensity band from $3,700 \mathrm{~cm}^{-1}$ to

$112,300 \mathrm{~cm}^{-1}$ and a band at $1,660 \mathrm{~cm}^{-1}$. This showed the appearance of carboxylic acid groups due

12 to the partial hydrolysis of ester groups of the PMMA sub-network. Furthermore, the $T_{\mathrm{g}, \text { onset }}$

13 values of IPNs after hydrolysis (see Table 6) were higherthan that of the corresponding PMMA

14 single network (i.e., $118^{\circ} \mathrm{C}$ ). As no mass loss was detected for thissingle network, it was possible

15 to hypothesize that the partial hydrolysis of PMMA sub-network was essentially due to the

16 hydrolysis of ester side groups in the PMMA sub-chains without degrading the main chain and

17 cross-linking points.

18 The morphologies of typicalIPNs after hydrolysis were examined by SEM (Fig. 7).It was

19 difficult to obtain images with a good resolution without degrading the materials during the SEM

20 analysis. Nevertheless, it is noteworthy that the residual networks typically exhibitednanoporous

21 structures with pore sizessmaller than $100 \mathrm{~nm}$. With such materials, the thermoporometry

22 technique was very useful to determine pore sizes and the pore size distributions. The pore size

23 ranges thus obtained are reported in Table 7, and pore size distributions are shown in Fig.6b.Pore

24 sizes were always smaller than $150 \mathrm{~nm}$, and thisresult mirrored the observations made from visual 
1 aspectsof IPNprecursors. As expected, compared to semi-IPN analogues, the pore diameters

2 were dramatically decreased due to the good chain interpenetration of both polyester and PMMA

3 sub-networks in the interlocking framework of IPN precursors. Moreover, as already

4 hypothesized from DSC analysis, the pore size increased with the oligoester precursor molar

5 mass, but no differences were noticed between PLA- and PCL-based IPN precursors. This meant

6 that domain sizes in IPNs were larger when the cross-linking density of the polyester sub-

7 network was smaller, regardless of the miscibility between PLA/PCL and PMMA. This result

8 was in a good agreement with literature reports $[25,46,47]$. As a matter of fact, when

9 synthesizing IPNs by the sequential method, the network first formed constitutes the most

10 continuous phase, and its cross-linking density generally determines the final morphology of the

11 system, while the cross-linking density of the second network has no significant effect.

12 Pore volumes of nanoporous networks were obtained through mass swelling

13 measurements in water and led to the determination of the apparent density and the porosity ratio

14 values (Table 8).Porosity ratios ranged from 33 to $42 \%$, which was lower than expected values,

15 taking into account the quantitative hydrolysis of polyester sub-network from polyester/PMMA

$16(50 / 50 \mathrm{wt} \%)$ IPNs. This was probably due to a partial collapse of the resulting porous structures.

17 Porosity ratio increasedwith the oligoester precursor molar mass, due tolarger pore sizes.

\section{Conclusions}

This contribution highlights the effectiveness and versatility of using oligoester-

22 derivatized semi-IPNs and IPNs as nanostructured precursors to porous networks with tunable

23 porosity.Miscellaneous PLA- or PCL-containing methacrylic (semi-)IPNs were indeed prepared 
1 as model systems from corresponding oligomers with different molar masses, and the pore sizes

2 of related porous materials could be correlated with the polyester domain sizes inferred from the

3 physico-chemical analysis of the (semi-)IPN precursors. Even though the quantitative extraction

4 of uncrosslinked oligoestersfrom semi-IPNs generally led to the formation of macroporous

5 networks, the semi-IPN approach constituted a straightforward and effective route toward

6 nanoporous networks provided the extent of miscibility between both semi-IPN partners was

7 high, i.e. when using the lower molar mass oligoester and preferably PLA. Alternatively, the

8 complete hydrolysis of the polyester sub-networkfrom IPNs afforded more versatility, since

9 nanoporous networks were generally derived therefrom, regardless of the molecularfeatures

10 associated with the oligoesters. The nanoporosity of residual porous networks could be attributed

11 to the good degree of chain interpenetration associated with both sub-networks in IPN precursors

12 arising from their peculiar interlocking framework. Still, pore sizes in nanoporous frameworks

13 increased with increasing oligoester molar masses, as the extent of microphase separation in IPNs

14 was larger when the crosslinking density of polyester sub-network decreased.

15 Such complementary routes involving semi-IPN and IPN systems may provide a 16 straightforward and facile means to tune the morphology associated with (nano-)porous

17 polymeric materials. Moreover, the functionalization of the pore surface through the initial 18 incorporation of functional monomers in the (semi-)IPNs precursors may allow for the

19 development ofa large variety of applications mainly expected in the areas of separation

20 techniques (chromatographic supports, selective membranes) and chemistry in confined media

21 (nanoreactors, catalytic supports).

\section{Conflict of interest statement}

24 On behalf of all authors, the corresponding author states that there is no conflict of interest. 


\section{$1 \quad$ References}

2 [1] Buchmeiser MR (2001) Angew Chem Int Ed 40:3795.

3 [2] Sykora D, Peters EC,Svec F, Fréchet JMJ (2000) Macromol Mater Eng 275:42.

4 [3] Hentze HP, Antonietti M. (2002) Rev Mol Biotech 90:27.

5 [4] Dauben M, Reichert KH, Huang P, Fock J (1996) Polymer 37:2827.

6 [5] Allender CJ, Richardson C, Woodhouse B, Heard CM, Brain KR (2000) Int J Pharm $7 \quad 195: 39$.

8 [6] Byrne ME, Oral E, Hilt JZ, Peppas NA (2002) Polym Adv Technol 13:798.

9 [7] Cameron NR (2004) Polymer 46:1439.

10 [8] Poupart R, Benlahoues A, Le Droumaguet B,Grande D (2017) ACS Appl Mater Interfaces $119: 31279$.

12 [9] Balaji R, Boileau S, Guérin P, Grande D (2004) Polym News 29:205.

13 [10] Wu D, Xu F, Sun B, Fu R, He H, Matyjaszewski K (2012) Chem Rev 112:3959.

14 [11] Kayaman-Apohan N, Baysal BM (2001) Macromol Chem Phys 202:1182.

15 [12] Widmaier JM, Sperling LH (1982)Macromolecules 15:625.

16 [13] Widmaier JM, Sperling LH (1984) Br Polym J 16: 46.

17 [14] Du Prez F, Goethals EJ (1995) Macromol Chem Phys 196:903.

18 [15] De Clercq RR, Goethals EJ (1992)Macromolecules 25:1109.

19 [16] Hu J, Pompe G, Schulze U, Pionteck J. (1998)Polym Adv Technol 9:746.

20 [17] Hu J, Schulze U Pionteck J (1999) Polymer 40:5279.

21 [18] Pionteck J, Hu J, Schulze U (2003) J Appl Polym Sci 89:1976.

22 [19] Sperling LH (1981) Interpenetrating Polymer Networks and Related Materials. Plenum 23 Press, New York. 
1 [20] Sperling LH (1988) In:Comprehensive Polymer Science. Pergamon Press, New York, Vol.

2 6, pp. $423-436$.

[21] Sperling LH, Mishra V (1996)Polym Adv Technol7:197.

[22] Kim SC, Sperling LH (1997) IPNs Around the World: Science and Engineering. Wiley, Chichester, UK.

[23] Athawale VD, Kolekar SL, Raut SS (2003) J Macromol Sci Part C: Polym RevC43:1.

[24] Thomas S, Grande D, Cvelbar U, Raju KVSN, Narayan R, Thomas S, Akhina H (2016) Micro- and Nano-Structured Interpenetrating Polymer Networks: From Design to Applications. John Wiley \& Sons, Hoboken, NJ.

[25] Dean K, Cook WD (2002)Macromolecules35:7942.

[26] Rohman G, Grande D, Lauprêtre F, Boileau S, Guérin P (2005)Macromolecules 38:7274.

[27] Rohman G, Lauprêtre F, Boileau S, Guérin P, Grande D (2007) Polymer 48:7017.

[28] Bachari A, Bélorgey G, Hélary G, Sauvet G (1995) Macromol Chem Phys 196:411.

[29] Brun M, Lallemand A, Quinson JF, Eyraud C. (1977)Thermochim. Acta 21:59.

[30] Iza M, Woerly S, Danumah C, Kaliaguine S, Bousmina M (2000) Polymer 41:5885.

[31] HayJN, Laity PR (2000)Polymer 41:6171.

[32] Rabelo D, Coutinho FMB (1993) Polym Bull 30:725.

[33] Okay O (2000)Prog Polym Sci 25:711.

[34] Eguiburu JL, Iruin JJ, Fernandez-Berridi MJ, San Roman J (1998) Polymer39:6891.

[35] Klein PG, Ebdon JR, Hourston DJ (1988) Polymer29:1079.

[36] Grulke EA (1999) In:Brandrup J, Immergut EH, Grulke EA (eds)Polymer Handbook, $4^{\text {th }}$ Ed. Wiley-Interscience, New York,p. VII/679.

[37] Coleman MM, Serman CJ, Bhagwagar DE, PainterPC (1990)Polymer 31:1187.

[38] Van Krevelen DW (1997) Properties of Polymers. Elsevier, Amsterdam. 
1 [39] Majdoub R, Dirany M, Benzina M, Grande D (2013) Matériaux \& Techniques 101:405.

2 [40] Grande D, Beurroies I, Denoyel R (2010) Macromol Symp 291:168.

3 [41] Grande D, Rohman G, Millot MC (2008)Polym Bull 61:129.

4 [42] Lav TX, Carbonnier B, Guerrouache M,Grande D (2010)Polymer 51:5890.

5 [43] Lav TX,Grande D, Gaillet C,Guerrouache M, Carbonnier B (2012)Macromol Chem Phys $6 \quad 213: 64$.

7 [44] Yan J, Wang XH, Chen J (2000)J Appl Polym Sci75:536.

8 [45] Wei J, Bai XY, Yan J (2003)Macromolecules36:4960.

9 [46] Donatelli AA,Sperling LH, Thomas DA (1976)Macromolecules9:671.

10 [47] Hourston DJ, Schäfer FU (1996)Polymer37:3521.

11

12 
Table 1 Molecular and thermal characteristics of oligoesters

\begin{tabular}{|c|c|c|c|c|c|c|c|}
\hline Nature & $\begin{array}{c}M_{\mathrm{n}}^{\mathrm{a}} \\
\left(\mathrm{g} \cdot \mathrm{mol}^{-1}\right)\end{array}$ & $\boldsymbol{\oplus}^{\mathbf{b}}$ & $\begin{array}{c}T_{\mathrm{g}} \mathbf{c} \\
\left({ }^{\circ} \mathbf{C}\right)\end{array}$ & $\begin{array}{c}\Delta C_{\mathrm{p}}^{\mathrm{d}} \\
\left(\mathrm{J} \cdot \mathrm{g}^{-1} \cdot{ }^{\circ} \mathbf{C}^{-1}\right)\end{array}$ & $\begin{array}{c}T_{\mathrm{m}} \\
\left({ }^{\circ} \mathrm{C}\right)\end{array}$ & $\begin{array}{c}\Delta H_{\mathrm{m}} \\
\left({\mathrm{J} . \mathrm{g}^{-1}}\right)\end{array}$ & $\begin{array}{l}X_{\mathrm{c}}^{\mathrm{e}} \\
(\%)\end{array}$ \\
\hline \multirow[t]{3}{*}{ PLA } & 570 & 1.2 & -20 & 0.57 & - & - & - \\
\hline & 1,700 & 1.2 & 10 & 0.55 & - & - & - \\
\hline & 3,700 & 1.4 & 25 & 0.61 & - & - & - \\
\hline \multirow[t]{2}{*}{ PCL } & 560 & 1.7 & -80 & 0.16 & 36 & 46.1 & 34 \\
\hline & 2,100 & 2.1 & -70 & 0.35 & 65 & 89.7 & 66 \\
\hline
\end{tabular}

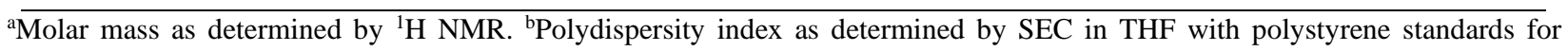
calibration. ${ }^{c} T_{\mathrm{g} v a l u e}$ as obtained at the midpoint. ${ }^{\mathrm{d}} \Delta C_{\mathrm{p}}=C_{\mathrm{p}, \mathrm{v}}-C_{\mathrm{p}, \mathrm{g}}$ : heat capacity jump at $T_{\mathrm{g}}$ as determined by DSC, where $C_{\mathrm{p}}$ is the heat capacity, the subscripts $v$ and $g$ refer to the "viscous" and "glassy" states, respectively. ${ }^{\mathrm{e}}$ crystallinity degree calculated with $\Delta H_{\mathrm{mo}}(100 \%$ crystalline PCL $)=135 \mathrm{J.g}^{-1}$. [Kweon HY, Yoo MK, Park IK, Kim TH, Lee HC, Lee HS, Oh JS, Akaike T, Cho CS (2003) Biomaterials 24:801] 
Table 2 Visual aspect and DSC analysis of semi-IPNs before and after extraction

\begin{tabular}{|c|c|c|c|c|c|c|c|}
\hline \multirow{2}{*}{$\begin{array}{l}\text { Oligoester nature } \\
\text { and molar mass }\end{array}$} & \multirow[b]{2}{*}{ Visual aspect $^{\text {a }}$} & \multicolumn{3}{|c|}{ Semi-IPNs before extraction } & \multicolumn{3}{|c|}{ Semi-IPNs after extraction } \\
\hline & & $\begin{array}{c}T_{\mathrm{g} \text { onset }} \\
\left({ }^{\circ} \mathrm{C}\right)\end{array}$ & $\begin{array}{l}\Delta T_{\mathrm{g}}{ }^{\mathrm{b}} \\
\left({ }^{\circ} \mathrm{C}\right)\end{array}$ & $\begin{array}{c}\Delta C_{\mathrm{p}}{ }^{\mathrm{c}} \\
\left(\mathrm{J} \cdot \mathrm{g}^{-1} \cdot{ }^{\circ} \mathrm{C}^{-1}\right)\end{array}$ & $\begin{array}{c}T_{\mathrm{g}, \text { onset }} \\
\left({ }^{\circ} \mathrm{C}\right)\end{array}$ & $\begin{array}{l}\Delta T_{\mathrm{g}}{ }^{\mathrm{b}} \\
\left({ }^{\circ} \mathrm{C}\right)\end{array}$ & $\begin{array}{c}\Delta C_{\mathrm{p}}^{\mathrm{c}} \\
\left(\mathrm{J} \cdot \mathrm{g}^{-1} \cdot{ }^{\circ} \mathrm{C}^{-1}\right)\end{array}$ \\
\hline PLA 570 g.mol ${ }^{-1}$ & $\overline{\operatorname{tr}}$ & -14 & 25 & 0.25 & 116 & 25 & 0.24 \\
\hline PLA 1,700 g. $\mathrm{mol}^{-1}$ & $\mathrm{tl}$ & 25 & 18 & 0.23 & 116 & 27 & 0.19 \\
\hline PLA 3,700 g.mol ${ }^{-1}$ & $\mathrm{o}$ & 39 & 13 & 0.19 & 106 & 31 & 0.23 \\
\hline PCL 560 g.mol ${ }^{-1}$ & tl & & 40 & 0.05 & 112 & 31 & 0.17 \\
\hline \multirow[t]{2}{*}{ PCL 2,100 g.mol ${ }^{-1}$} & \multirow[t]{2}{*}{ o } & $\begin{array}{l}\left(T_{\mathrm{m}}=3\right. \\
-65\end{array}$ & $\begin{array}{c}\Delta H_{\mathrm{m}}=2 \\
38\end{array}$ & $\begin{array}{c}\left.\mathrm{g}^{-1}, X_{\mathrm{c}}^{\mathrm{d}}=16 \%\right) \\
0.18\end{array}$ & \multirow[t]{2}{*}{117} & \multirow[t]{2}{*}{25} & \multirow[t]{2}{*}{0.18} \\
\hline & & $\left(T_{\mathrm{m}}=6\right.$ & $\Delta H_{\mathrm{m}}=$ & $\left.\mathrm{g}^{-1}, X_{\mathrm{c}}^{\mathrm{d}}=30 \%\right)$ & & & \\
\hline
\end{tabular}

${ }^{\mathrm{a}} \mathrm{o}$ : opaque, tl: translucent, tr: transparent. ${ }^{\mathrm{b}} \Delta T_{\mathrm{g}}=T_{\mathrm{g}, \text { end }}-T_{\mathrm{g}, \text { onset: }}$ range of temperatures in which the glass transition occurs as determined by DSC. ${ }^{\mathrm{c}} \Delta C_{\mathrm{p}}=C_{\mathrm{p}, \mathrm{v}}-C_{\mathrm{p}, \mathrm{g}}$ : heat capacity jump at $\mathrm{T}_{\mathrm{g}}$ as determined by DSC, where $C_{\mathrm{p}}$ is the heat capacity, the subscripts $\mathrm{v}$ and g refer to the "viscous" and "glassy" states, respectively. "crystallinity degree calculated with $\Delta H_{\mathrm{m} 0}(100 \%$

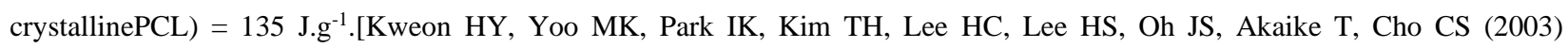
Biomaterials 24:801] 
Table 3 DSC analysis of polyester and PMMA single networks

\begin{tabular}{|c|c|c|c|c|}
\hline & $\begin{array}{c}\text { Oligoester nature and } \\
\text { molar mass }\end{array}$ & $\begin{array}{c}\boldsymbol{T}_{\mathrm{g}, \text { onset }} \\
\left({ }^{\circ} \mathbf{C}\right)\end{array}$ & $\begin{array}{l}\Delta T_{\mathrm{g}}^{\mathrm{a}} \\
\left({ }^{\circ} \mathrm{C}\right)\end{array}$ & 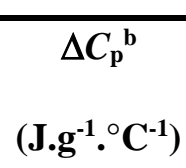 \\
\hline \multirow[t]{6}{*}{ Polyester single networks } & PLA 570 g.mol ${ }^{-1}$ & 50 & 30 & 0.32 \\
\hline & PLA 1,700 g.mol ${ }^{-1}$ & 20 & 25 & 0.29 \\
\hline & PLA 3,700 g.mol ${ }^{-1}$ & 30 & 15 & 0.27 \\
\hline & PCL 560 g.mol ${ }^{-1}$ & -5 & 25 & 0.28 \\
\hline & PCL $2100 \% \mathrm{~mol}^{-1}$ & -55 & 10 & 0.32 \\
\hline & & \multicolumn{3}{|c|}{$\left(T_{\mathrm{m}}=50^{\circ} \mathrm{C}, \Delta H_{\mathrm{m}}=4 \mathrm{~J}_{\mathrm{g}} \mathrm{g}^{-1}\right)$} \\
\hline PMMA single network & - & 118 & 19 & 0.16 \\
\hline
\end{tabular}


Table 4 Variations of $\chi_{\mathrm{cr}}$ with oligoester nature and molar massfor 10 mol\% DUDMAbasedsystems

\begin{tabular}{cc}
\hline $\begin{array}{c}\text { Oligoester nature and } \\
\text { molar mass }\end{array}$ & $\chi_{\mathrm{cr}}$ \\
\hline PLA $570 \mathrm{~g} \cdot \mathrm{mol}^{-1}$ & $0.32 \pm 5 \cdot 10^{-3}$ \\
PLA 1,700 g.mol ${ }^{-1}$ & $0.21 \pm 5 \cdot 10^{-3}$ \\
PLA 3,700 g.mol ${ }^{-1}$ & $0.17 \pm 5 \cdot 10^{-3}$ \\
\hline PCL 560 g.mol ${ }^{-1}$ & $0.34 \pm 5 \cdot 10^{-3}$ \\
PCL 2,100 g.mol ${ }^{-1}$ & $0.24 \pm 5 \cdot 10^{-3}$ \\
\hline
\end{tabular}


Table 5 Soluble fractions associated with single networks and polyester/PMMA (50/50 wt\%) (semi-)IPNsafter extraction as well asmass loss associated with polyester/PMMA (50/50 wt\%) IPNs after hydrolysis $^{\text {a }}$

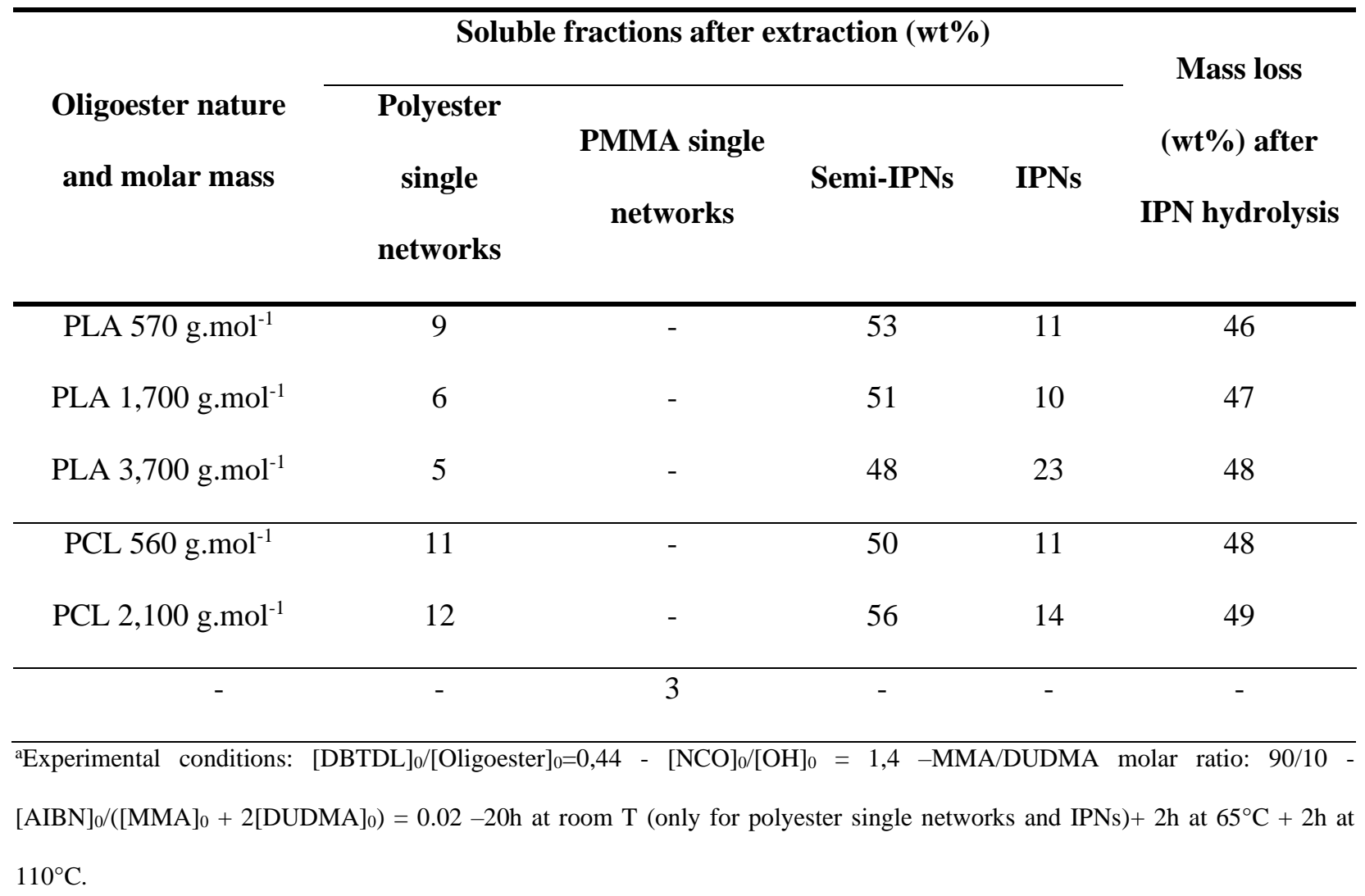


Table 6 DSC analysis of IPNs before and after hydrolysis

\begin{tabular}{|c|c|c|c|c|c|c|}
\hline \multirow{2}{*}{$\begin{array}{l}\text { Oligoester nature } \\
\text { and molar mass }\end{array}$} & \multicolumn{3}{|c|}{ IPNs before hydrolysis } & \multicolumn{3}{|c|}{ IPNs after hydrolysis } \\
\hline & $\begin{array}{c}T_{\mathrm{g}, \text { onset }} \\
\left({ }^{\circ} \mathrm{C}\right)\end{array}$ & $\begin{array}{l}\Delta T_{\mathrm{g}}{ }^{\mathrm{a}} \\
\left({ }^{\circ} \mathrm{C}\right)\end{array}$ & $\begin{array}{c}\Delta C_{\mathrm{p}}^{\mathrm{b}} \\
\left(\mathrm{J} \cdot \mathrm{g}^{-1} \cdot{ }^{\circ} \mathrm{C}^{-1}\right)\end{array}$ & $\begin{array}{c}T_{\mathrm{g}, \text { onset }} \\
\left({ }^{\circ} \mathrm{C}\right)\end{array}$ & $\begin{array}{l}\Delta T_{\mathrm{g}}{ }^{\mathrm{a}} \\
\left({ }^{\circ} \mathrm{C}\right)\end{array}$ & $\begin{array}{c}\Delta C_{\mathrm{p}}^{\mathrm{b}} \\
\left(\mathrm{J} \cdot \mathrm{g}^{-1} \cdot{ }^{\circ} \mathrm{C}^{-1}\right)\end{array}$ \\
\hline PLA 570 g.mol ${ }^{-1}$ & 58 & 35 & 0.26 & 122 & 23 & 0.21 \\
\hline PLA 1,700 g.mol ${ }^{-1}$ & 45 & 46 & 0.22 & 128 & 16 & 0.15 \\
\hline PLA 3,700 g. $\mathrm{mol}^{-1}$ & 45 & 49 & 0.22 & 126 & 19 & 0.21 \\
\hline PCL 560 g.mol ${ }^{-1}$ & 38 & 32 & 0.23 & 121 & 15 & 0.19 \\
\hline PCL 2,100 g. $\mathrm{mol}^{-1}$ & -50 & 52 & 0.14 & 126 & 20 & 0.19 \\
\hline
\end{tabular}

${ }^{\mathrm{a}} \Delta T_{\mathrm{g}}=T_{\mathrm{g}, \text { end }}-T_{\mathrm{g}, \text { onset: }}$ range of temperatures in which the glass transition occurs as determined by DSC. ${ }^{\mathrm{b}} \Delta C_{\mathrm{p}}=C_{\mathrm{p}, \mathrm{v}}-C_{\mathrm{p}, \mathrm{g}}$ : heat capacity jump at $T_{\mathrm{g}}$ as determined by DSC, where $C_{\mathrm{p}}$ is the heat capacity, the subscripts $\mathrm{v}$ and $\mathrm{g}$ refer to the "viscous" and "glassy" states, respectively. 
Table 7 Pore diameters of resulting porous networksafter extraction of semi-IPNs orhydrolysis of IPNs as determined by SEM and DSC-based thermoporometry

\begin{tabular}{|c|c|c|c|}
\hline \multirow{3}{*}{$\begin{array}{l}\text { Oligoester nature } \\
\text { and molar mass }\end{array}$} & \multicolumn{3}{|c|}{ Pore diameters } \\
\hline & \multicolumn{2}{|c|}{ Semi-IPNs } & \multirow{2}{*}{$\begin{array}{c}\text { IPNs } \\
\text { DSC (nm) }\end{array}$} \\
\hline & SEM (nm) & DSC (nm) & \\
\hline PLA 570 g.mol ${ }^{-1}$ & $10-75$ & $40-115$ & $17-75$ \\
\hline PLA 1,700 g.mol ${ }^{-1}$ & $25-150$ & $30-140$ & $20-80$ \\
\hline PLA 3,700 g. $\mathrm{mol}^{-1}$ & $75-450$ & $10-200^{a}$ & $30-150$ \\
\hline PCL 560 g.mol ${ }^{-1}$ & $25-150$ & $50-170$ & $20-65$ \\
\hline PCL 2,100 g.mol ${ }^{-1}$ & $150-1,000$ & $10-200^{a}$ & $20-95$ \\
\hline
\end{tabular}

aDSC-based thermoporometry only allowed for determination of pore size up to $200 \mathrm{~nm}$. For larger pore sizes, the melting peaks of confined and bulk water were not resolved: confined water just behaved as a bulk solvent. 
Table 8 Pore volume $\left(V_{\text {pore }}\right)$, apparent density $\left(d_{\text {app }}\right)$, and porosity ratio $(P)$ of resulting porousnetworks after extraction of semi-IPNs or hydrolysis of IPNs

\begin{tabular}{|c|c|c|c|c|c|c|}
\hline \multirow{2}{*}{$\begin{array}{l}\text { Oligoester nature } \\
\text { and molar mass }\end{array}$} & \multicolumn{3}{|c|}{ Semi-IPNs } & \multicolumn{3}{|c|}{ IPNs } \\
\hline & $\begin{array}{c}V_{\text {pore }} \\
\left(\mathrm{cm}^{3} \cdot \mathrm{g}^{-1}\right)\end{array}$ & $d_{\text {app }}$ & $P$ & $\begin{array}{c}V_{\text {pore }} \\
\left(\mathrm{cm}^{3} \cdot \mathrm{g}^{-1}\right)\end{array}$ & $d_{\mathrm{app}}$ & $P$ \\
\hline PLA 570 g. $\mathrm{mol}^{-1}$ & 0.87 & 0.59 & 0.51 & 0.42 & 0.80 & 0.33 \\
\hline PLA $1,700 \mathrm{~g} \cdot \mathrm{mol}^{-1}$ & 0.89 & 0.58 & 0.52 & 0.55 & 0.72 & 0.40 \\
\hline PLA 3,700 g.mol ${ }^{-1}$ & 0.86 & 0.59 & 0.51 & 0.54 & 0.72 & 0.40 \\
\hline PCL 560 g. $\mathrm{mol}^{-1}$ & 0.84 & 0.59 & 0.50 & 0.42 & 0.79 & 0.34 \\
\hline PCL 2,100 g. $\mathrm{mol}^{-1}$ & 0.83 & 0.60 & 0.50 & 0.60 & 0.69 & 0.42 \\
\hline
\end{tabular}




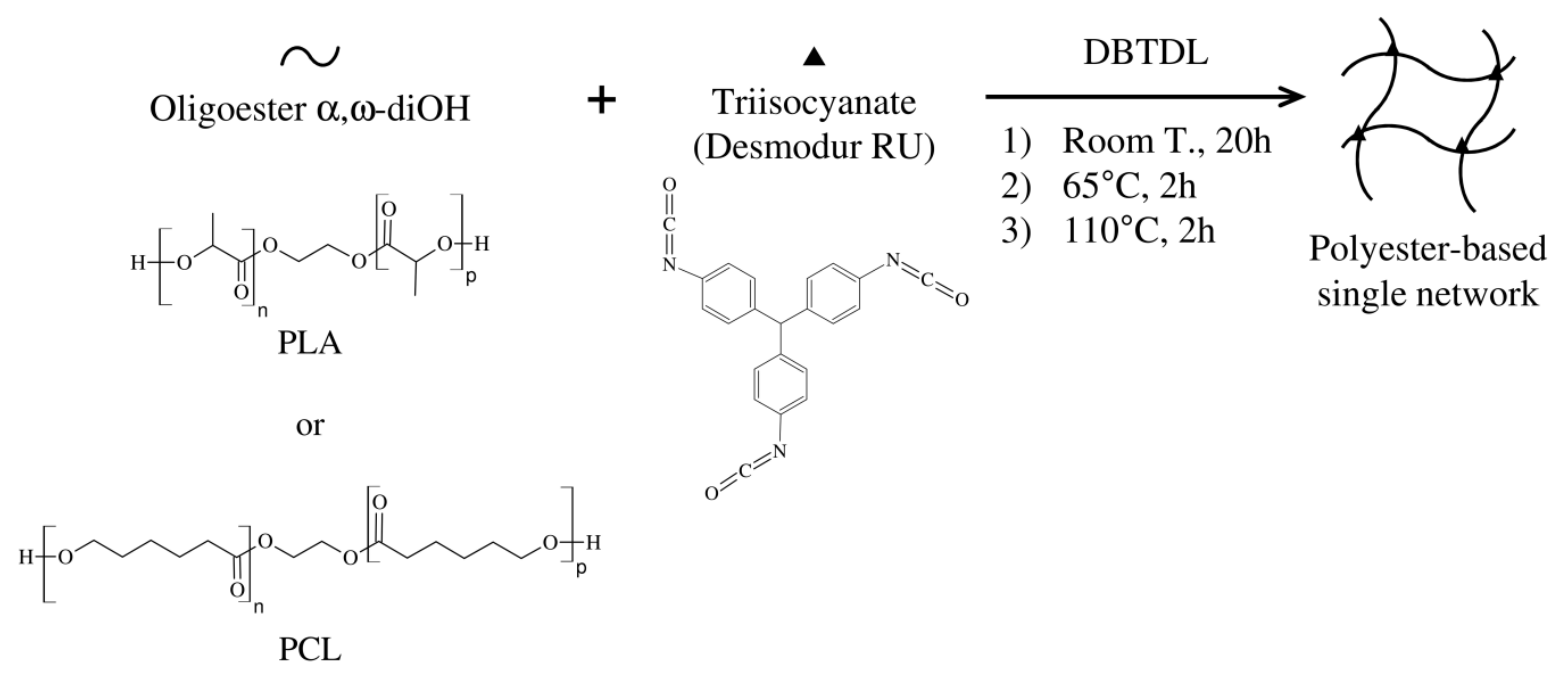

Fig. 1 Preparation of polyester-based single networks
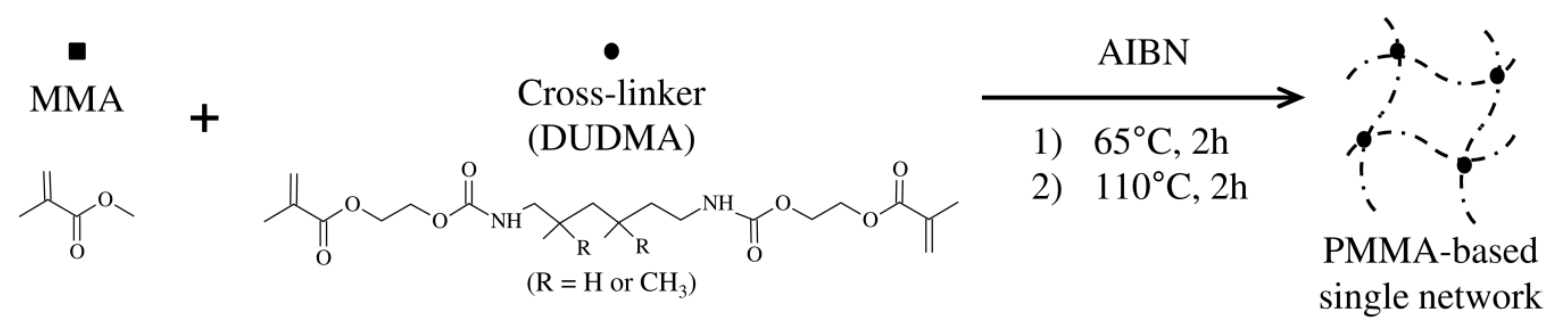

Fig. 2 Preparation of PMMA-based single networks

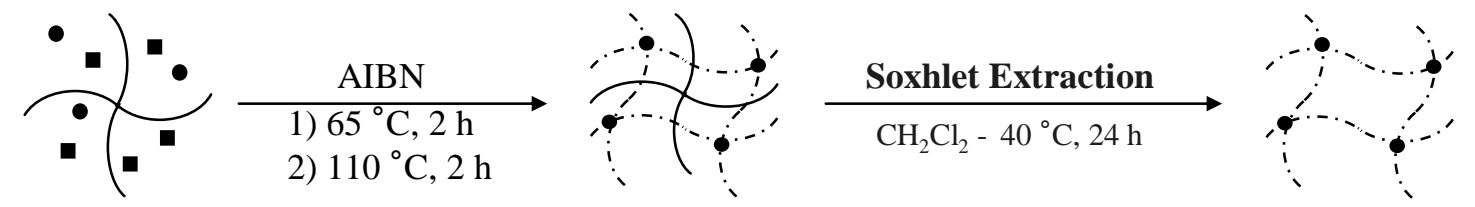

$\sim \alpha, \omega$-diOH oligoester

- MMA

- DUDMA $\underline{\text { Oligoester/PMMA }}$

semi-IPN $\underline{\text { Residual Porous }}$ Methacrylic network

Fig.3 Synthesis of oligoester/PMMA-based semi-IPNs and design of porous PMMA networks derived therefrom 


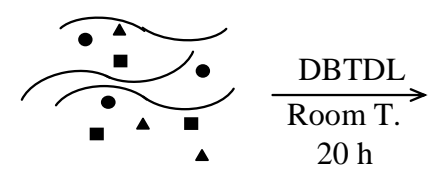

$\sim \alpha, \omega$-diOH oligoester

^ Triisocyanate

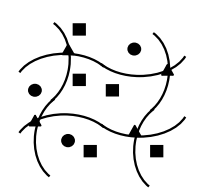

- MMA

- DUDMA

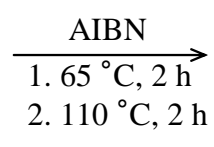

Polyester/PMMA

$\underline{\text { IPN }}$

1. Soxhlet Extraction

$\mathrm{CH}_{2} \mathrm{Cl}_{2}-40{ }^{\circ} \mathrm{C}, 24 \mathrm{~h}$

2. Partial Hydrolysis

Residual Porous

Methacrylic Network

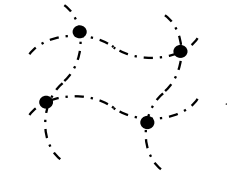

Methylamine ( $\mathrm{pH}=13.6) /$ Ethanol $(50 / 50 \mathrm{vol} \%)$

$60{ }^{\circ} \mathrm{C}, 24 \mathrm{~h}$

Fig.4 Synthesis of polyester/PMMA-based IPNs and design of porous methacrylic networks derived therefrom
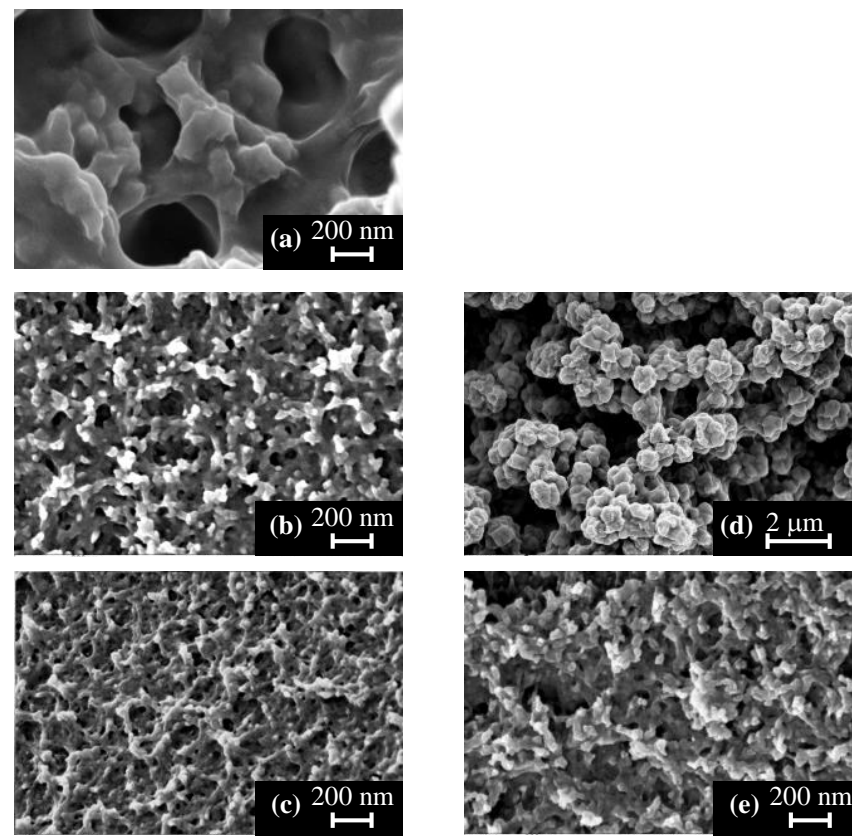

Fig. 5 SEM micrographs of porous networks derived from extraction of oligoester/PMMA (50/50 wt\%) semi-IPNs:PLA-based systems: (a) 3,700 g. $\mathrm{mol}^{-1}$, (b) 1,700 g. $\mathrm{mol}^{-1}$, (c) 560 g.mol ${ }^{-1}$;PCL-based systems: (d) 2,100 g. $\mathrm{mol}^{-1}$, (e) 570 g.mol ${ }^{-1}$ 

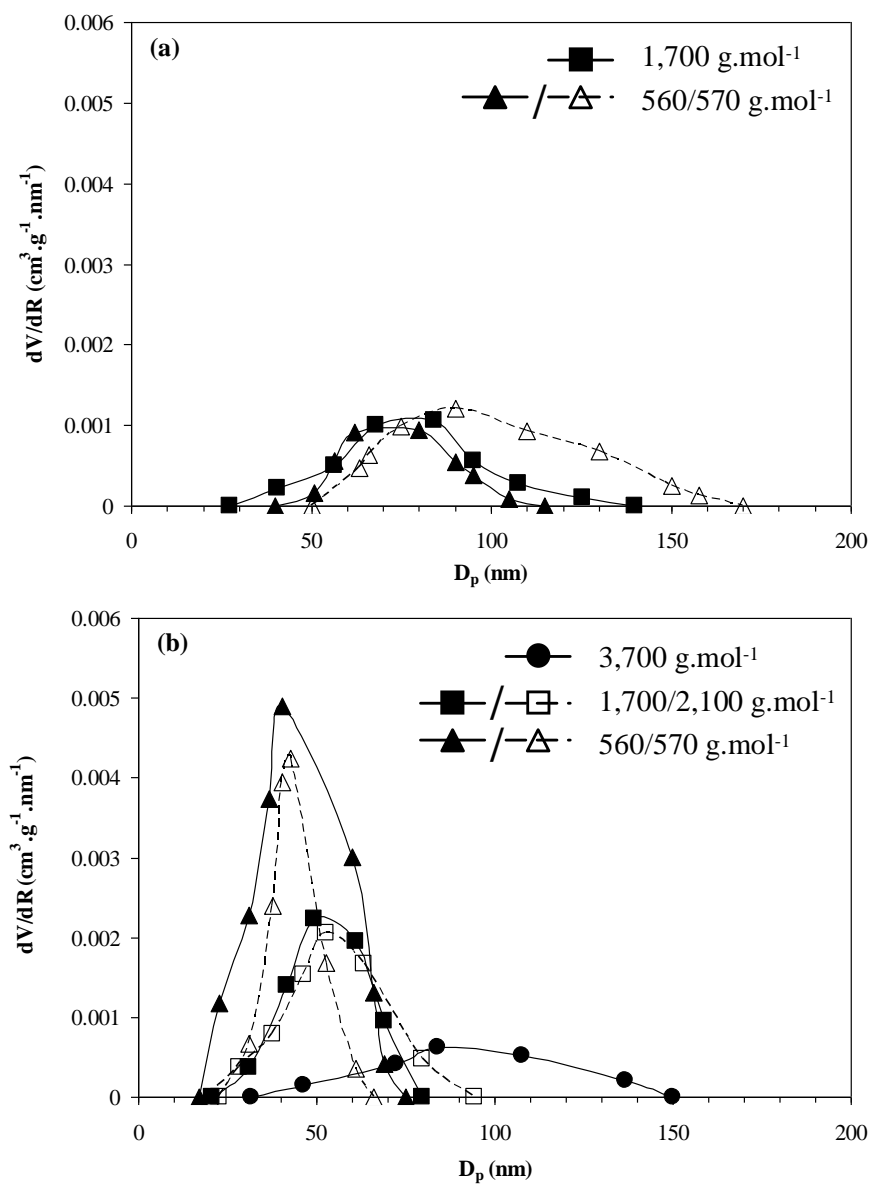

Fig. 6 Pore size distribution profiles of porous methacrylic networks as determined by DSCbased thermoporometry for PLA- (full symbols) and PCL- (empty symbols) containing systems with varying oligoester molar masses: (a) semi-IPNs after extraction, (b) IPNs after hydrolysis 

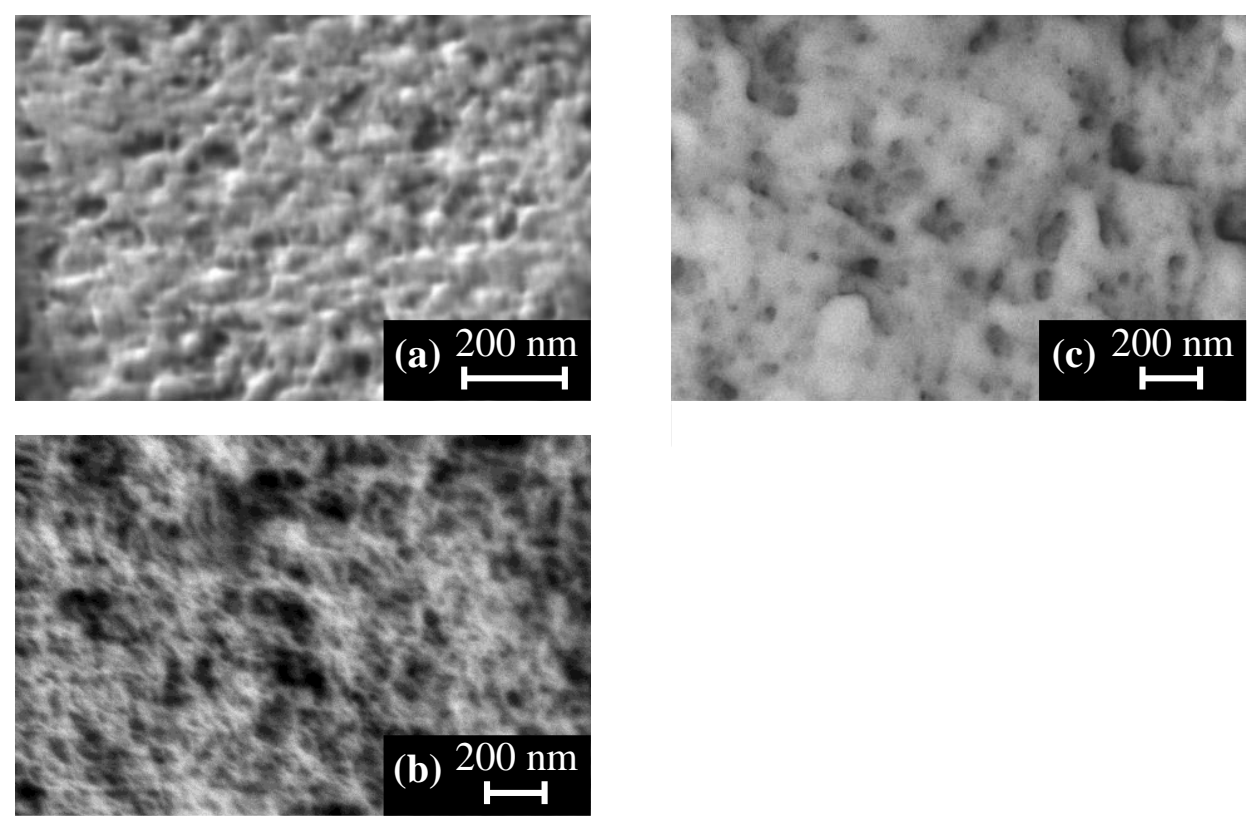

Fig. 7 SEM micrographs of porous networks derived from partial hydrolysis of polyester/PMMA (50/50 wt\%) IPNs:PLA-based systems: (a) 1,700 g. $\mathrm{mol}^{-1}$, (b) $560 \mathrm{~g} \cdot \mathrm{mol}^{-}$ ${ }^{1}$;PCL-based systems: (c) 2,100 g.mol ${ }^{-1}$ 